\title{
Assessment of Anemia as a Risk Factor for Acute Lower Respiratory Tract Infections in Children: A Case-Control Study
}

\author{
Roma Kmª, d, Veena Gupta ${ }^{\text {a }}$, Shakil Ahmad ${ }^{\text {a }}$, Singh Ranhotra ${ }^{\text {a }}$, Rakhi Issrani ${ }^{\text {, }}$ \\ Namdeo Prabhu ${ }^{\mathrm{c}}$
}

\begin{abstract}
Background: Anemia is a major nutritional universal problem of immense public health significance, affecting persons of all ages, sex and economic group. Acute lower respiratory tract infection (ALRTI) is a major cause of death in less than 5 years of age, and anemia is the commonest co-factor in pediatric patients seeking medical advice. There is little contemporary literature outlining the relationship between anemia and lower respiratory tract infection (LRTI) in children especially in our country Nepal. Hence, it was decided to conduct a study to determine the relationship between anemia and ALRTI. The study was to assess anemia as a risk factor for ALRTI in Nepalese children aged from 6 months to 5 years.
\end{abstract}

Methods: Two hundred children from 6 months to 5 years who attended the outpatient department and those admitted to the ward were included in the study. One hundred children with ALRTI were taken as the study group, and another 100 age- and sex-matched children without ALRTI were taken as the control. The study period was from July 2013 to June 2014. Complete blood count and peripheral blood smear were done in all children. A child with hemoglobin below 11 $\mathrm{g} \%$ was considered anemic. Serum iron, serum ferritin level and total iron binding capacity were estimated for all anemic children. LRTI cases were diagnosed by WHO criteria. Chest radiographs were taken for all ALRTI cases.

Results: Anemia was found in $72 \%$ of cases and $34 \%$ of controls. Mean hemoglobin level was $9.2 \mathrm{~g} \%$ and $11.4 \mathrm{~g} \%$ in cases and controls respectively with a significant $\mathrm{P}$ value of $<0.05$. Iron deficiency was found in $86 \%$ of total anemic children of study group and $63 \%$ children of control group.

Manuscript accepted for publication September 29, 2015

aDepartment of Pediatrics, Nepalgunj Medical College, Nepalgunj, Nepal ${ }^{b}$ Department of Oral Medicine and Radiology, Saraswati Medical and Dental College, 233, Tiwariganj, Faizabad Road, Lucknow 227105, Uttar Pradesh, India

'Department of Oral and Maxillofacial Surgery, Saraswati Medical and Dental College, 233, Tiwariganj, Faizabad Road, Lucknow 227105, Uttar Pradesh, India

${ }^{\mathrm{d} C o r r e s p o n d i n g ~ A u t h o r: ~ R o m a ~ K m, ~ D e p a r t m e n t ~ o f ~ P e d i a t r i c s, ~ N e p a l g u n j ~}$ Medical College, Nepalgunj, Nepal. Email: bora.roma@gmail.com

doi: http://dx.doi.org/10.14740/ijcp220w
Conclusions: Anemic children were found to be 4.99 times more susceptible to ALRTI compared to the non-ALRTI control group, and iron deficiency anemia was predominating. Early diagnosis and management might prevent the occurrence of ALRTI.

Keywords: Anemia; Hemoglobin; Iron deficiency anemia; Acute lower respiratory tract infections

\section{Introduction}

Anemia is characterized by a decreased quantity of red blood cells, often accompanied by diminished hemoglobin levels or altered red blood cell morphology [1]. It is a major global nutritional problem of immense public health significance, affecting people of all ages, sex and economic group [2]. Among various nutritional deficiency anemias, iron deficiency anemia (IDA) is the commonest [3].

Lower respiratory tract infection (LRTI) includes all infections of the lungs and the large airways below the larynx [4]. Acute lower respiratory tract infections (ALRTIs) are responsible for $19 \%$ of all deaths in children less than 5 years of age and $8.2 \%$ of all disabilities and premature mortality as measured by disability-adjusted life years [5]. In ALRTI, pneumonia is the biggest cause of death under the age of 5 years. Every year approximately 150 million episodes of childhood pneumonia and about 3 million deaths due to pneumonia are reported worldwide in children less than 5 years of age [6].

Low hemoglobin may also be a risk factor for ALRTI along with many other risk factors like low birth weight, lack of breast feeding, severe malnutrition, smoke, etc. IDA in children occurs most frequently between the ages from 6 months to 3 years [2]. Both IDA and ALRTI are more common in developing countries than in developed countries. Simple intervention with cheap, dependable and cost-effective prevention of LRTI with iron supplementation in children below 5 years of age may reduce incidence of morbidity and mortality.

There is little contemporary literature outlining the relationship between anemia and LRTI in children especially in our country Nepal. Against this backdrop, the present study was conducted with the aim to determine the relationship between anemia and ALRTI in Nepalese children. 
Table 1. Age and Gender Distribution of Cases and Controls

\begin{tabular}{|c|c|c|c|c|c|c|c|c|}
\hline & \multicolumn{8}{|c|}{ Age (months) } \\
\hline & \multicolumn{4}{|c|}{ Cases } & \multicolumn{4}{|c|}{ Controls } \\
\hline & $7-24$ & $25-42$ & $43-60$ & Total & $7-24$ & $25-42$ & $43-60$ & Total \\
\hline Male & 44 & 6 & 3 & 53 & 46 & 4 & 2 & 52 \\
\hline Female & 35 & 8 & 4 & 47 & 36 & 9 & 3 & 48 \\
\hline Total & 79 & 14 & 7 & 100 & 82 & 13 & 5 & 100 \\
\hline
\end{tabular}

\section{Materials and Methods}

The research protocol for this study was reviewed and approved by the Institutional Review Board committee of Nepalgunj Medical College (NGMC), Banke, Nepal.

\section{Study design}

A case-control study was conducted at NGMC, Nepal for a period of 1 year from July 2013 to June 2014 in pediatric department.

\section{Study population}

The sample frame consisted of 200 children (100 cases and

Table 2. Clinical Features of Cases and Controls

\begin{tabular}{|llll}
\hline Clinical features & $\begin{array}{l}\text { Cases } \\
(\%)\end{array}$ & $\begin{array}{l}\text { Controls } \\
(\%)\end{array}$ & P value \\
\hline Symptoms & 100 & 3 & 0.00 \\
$\quad$ Cough & 88 & 82 & 0.23 \\
\hline Fever & 79 & 3 & 0.00 \\
\hline Fast breathing & 30 & 25 & 0.42 \\
\hline Poor feeding & 21 & 0 & 0.00 \\
\hline Noisy breathing & 5 & 23 & 0.00 \\
\hline Convulsions & 9 & 21 & 0.17 \\
\hline Vomiting & 11 & 40 & 0.00 \\
\hline Loose stools & 17 & 19 & 0.71 \\
\hline Irritability & 3 & 18 & 0.01 \\
\hline Abdominal pain & 0 & 7 & 0.007 \\
\hline Sore throat & & & \\
Signs & 5 & 0 & 0.24 \\
\hline Cyanosis & 63 & 0 & 0.00 \\
\hline Chest indrawings & 29 & 0 & 0.00 \\
\hline Rhonchi & 41 & 0 & 0.00 \\
Crepitations & 13 & 0 & 0.00 \\
\hline Crepitations and rhonchi & 4 & 28 & 0.00 \\
\hline Dehydration & & & \\
\hline
\end{tabular}

100 controls) aged between 6 months and 5 years attending the outpatient department and those hospitalized. Age- and sexmatched 100 children, attending the pediatric outpatient department or hospitalized with complaints of illness other than ALRTI were randomly selected as controls.

\section{Inclusion criteria}

The inclusion criteria for cases were children aged between 6 months and 5 years with a diagnosis of ALRTI.

\section{Exclusion criteria}

Children with the following criteria were exempted from this study: 1) congenital malformations of chest wall; 2) having severe systemic illness; 3) protein energy malnutrition (PEM $>$ grade III as per Indian Academy of Pediatrics classification) [7]; and 4) intake of iron supplements.

\section{Study procedure}

A written consent was taken from parents or guardians of children before they were subjected to investigations. After informed consent, detailed history was elicited and physical examination was done. Weight and height were recorded to all children in order to assess the nutritional status. History of relevant symptoms like fever, cough, rapid breathing, chest retractions, refusal of feeds, lethargy, wheeze, etc., was taken. Hospital records were also examined for relevant data.

The following investigations were done in all children at NGMC clinical laboratory: complete blood count (CBC) and peripheral blood smear (PBS). Hemoglobin level $<11 \mathrm{~g} \%$ was considered low in this study [8]. Serum iron, serum ferritin and total iron binding capacity (TIBC) were done if hemoglobin level was below $11 \mathrm{~g} \%$. Chest radiograph was done in all ALRTI cases.

Blood sample were taken from antecubital vein of each child by a trained phlebotomist. Sterile, disposable syringes and needles, and proper tubes were used. Hemoglobin level was estimated in the blood samples using cyanmeth method by automatic blood cell analyzer. CBC was quantified using fully automatic complete analyzer. Serum iron level and TIBC were measured by using the ferrozine method without deproteinization. Serum ferritin was assessed utilizing chemiluminescence 


\section{$\square$ Normal $\square$ Pneumonia $\square$ Hyperinflation}

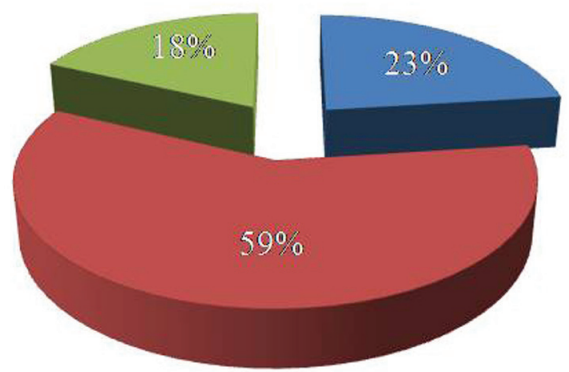

Figure 1. Radiographic findings of cases.

immunoassay.

\section{Statistical analysis}

Data entry was done in Microsoft excel 2007 and analysis was done using statistical package for social sciences (SPSS 20 version). Categorical variables were reported in terms of numbers and percentages. Association of each of the categorical variable with response variable was assessed by Chi-square test. Bivariate analysis was done between demographic, clinical variable and ALRTI using " $t$ "-independent test and presented with $\mathrm{P}$ value.

\section{Results}

A total of 200 children (100 cases and 100 controls) aged between 6 months and 5 years were enrolled in the study. Among cases, $53 \%$ were males and $47 \%$ females whereas among con-
Table 3. Hemoglobin Level Among Anemic and Non-Anemic Patients

\begin{tabular}{lllll} 
& & & OR $(\mathbf{9 5} \% \mathbf{C I})$ & P value \\
\hline $\mathrm{Hb} \leq 11 \mathrm{~g} / \mathrm{dL}$ & 72 & 34 & $4.99(2.73-9.1)$ & 0.00 \\
$\mathrm{Hb}>11 \mathrm{~g} / \mathrm{dL}$ & 28 & 66 & - & - \\
\hline
\end{tabular}

trols, $52 \%$ were males and $48 \%$ females. Among 100 cases, 79 (44 males and 35 females) were in the age group of $7-24$ months, 14 (six males and eight females) were in between 25 - 42 months and seven (three males and four females) were in the age group of 43 - 60 months. Similarly for control group the age distribution for 82 ( 46 males and 36 females), 13 (four males and nine females), and five (two males and three females) in the age group of 7 - 24 months, 25 - 42 months and 43 - 60 months, respectively (Table 1). Among the demographic variables, age and sex, both were not statistically significant variables for ALRTI $(\mathrm{P}>0.05)$.

Cough, fever and fast breathing were main symptoms observed in $100 \%, 88 \%$ and $79 \%$ cases, respectively, whereas fever, loose stools and poor feeding were main symptoms observed in $82 \%, 40 \%$ and $25 \%$ controls, respectively. Among signs, chest indrawing was present in $63 \%$ cases and cyanosis in $5 \%$ cases. Auscultatory chest findings revealed crepitations in $41 \%$, rhonchi in $29 \%$, and both crepitations and rhonchi in $13 \%$ patients. Dehydration was the main sign found in $28 \%$ controls (Table 2).

Among cases, radiological evidence of pneumonia was present in 59\% patients, hyperinflated lungs suggestive of bronchiolitis in $18 \%$ patients and chest radiograph was normal in $23 \%$ patients (Fig. 1).

The mean hemoglobin level was $9.2 \mathrm{~g} \%$ for study group and $11.4 \mathrm{~g} \%$ for control group (Fig. 2). The $72 \%$ of study group and $34 \%$ of control group had anemia. Categorical variable anemia was statistically significant with odds ratio (OR) of $4.99,95 \%$ CI (2.73 - 9.1) shows presence of anemia which increases the risk of ALRTI by 4.99 times as compared to non-

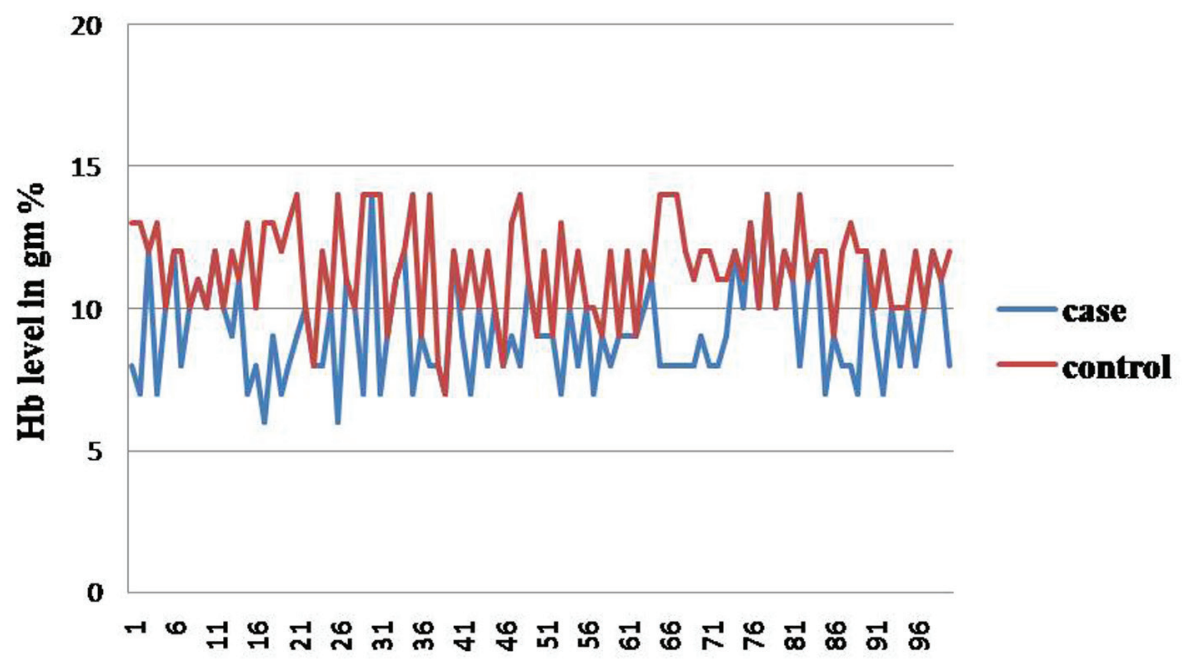

Figure 2. Range of hemoglobin of cases and controls. 
Table 4. Age and Gender Distribution of Anemic Cases and Controls

\begin{tabular}{|c|c|c|c|c|c|c|c|c|c|c|c|c|c|c|}
\hline & \multicolumn{7}{|c|}{ Cases } & \multicolumn{7}{|c|}{ Controls } \\
\hline \multicolumn{15}{|l|}{ Anemia } \\
\hline Age (months) & \multicolumn{2}{|c|}{$7-24$} & \multicolumn{2}{|c|}{$25-42$} & \multicolumn{2}{|c|}{$43-60$} & \multirow[t]{2}{*}{ Total } & \multicolumn{2}{|c|}{$7-24$} & \multicolumn{2}{|c|}{$25-42$} & \multicolumn{2}{|c|}{$43-60$} & Total \\
\hline Gender & $\mathrm{M}$ & $\mathrm{F}$ & M & $\mathrm{F}$ & M & $\mathrm{F}$ & & $\mathrm{M}$ & $\mathrm{F}$ & $\mathrm{M}$ & $\mathrm{F}$ & $\mathrm{M}$ & $\mathrm{F}$ & \\
\hline $\mathrm{n}$ & 29 & 25 & 6 & 5 & 3 & 4 & 72 & 16 & 13 & 2 & 1 & 1 & 1 & 34 \\
\hline \multicolumn{15}{|l|}{ IDA } \\
\hline Age (months) & \multicolumn{2}{|c|}{$7-24$} & \multicolumn{2}{|c|}{$25-42$} & \multicolumn{2}{|c|}{$43-60$} & Total & \multicolumn{2}{|c|}{$7-24$} & \multicolumn{2}{|c|}{$25-42$} & \multicolumn{2}{|c|}{$43-60$} & Total \\
\hline Gender & M & $\mathrm{F}$ & M & $\mathrm{F}$ & M & $\mathrm{F}$ & & $\mathrm{M}$ & $\mathrm{F}$ & M & $\mathrm{F}$ & M & $\mathrm{F}$ & \\
\hline $\mathrm{n}$ & 24 & 23 & 5 & 5 & 3 & 2 & 62 & 11 & 8 & 1 & 0 & 0 & 1 & 21 \\
\hline
\end{tabular}

anemic patient (Table 3). Among the anemic children, maximum children belonged to the age group of $7-24$ months for both the groups (Table 4).

Among the anemic children, $62(86 \%)$ in study group had iron deficiency, with mean MCV $64.49 \mathrm{fL}$, mean MCH $19.92 \mathrm{pg}$, mean MCHC $31.13 \mathrm{~g} / \mathrm{dL}$, mean RDW 17.07\%, mean serum iron $36 \mu \mathrm{g} / \mathrm{dL}$, mean serum ferritin $40.21 \mathrm{ng} / \mathrm{mL}$ and mean TIBC $396 \mu \mathrm{g} / \mathrm{dL}$. For the control group, the values were $21(63 \%)$ with iron deficiency, having mean MCV $78.36 \mathrm{fL}$, mean MCH 25.97 pg, mean MCHC $32.52 \mathrm{~g} / \mathrm{dL}$, mean RDW $13.82 \%$, mean serum iron $71 \mu \mathrm{g} / \mathrm{dL}$, mean serum ferritin 85.15 $\mathrm{ng} / \mathrm{mL}$ and mean TIBC $328 \mu \mathrm{g} / \mathrm{dL}$.

All the clinical parameters of anemia including hemoglobin, $\mathrm{MCV}, \mathrm{MCH}, \mathrm{MCHC}$, RDW, serum iron, serum ferritin and TIBC were statistically significant for ALRTI with $P$ value $<0.01$ (Table 5).

\section{Discussion}

The prevalence of anemia varies between developed and developing countries being more prevalent in developing countries with prevalence of $44-74 \%$ in children [4]. IDA is the most common cause of anemia [9]. The $46 \%$ of children in Nepal are anemic, $27 \%$ are mildly anemic, $18 \%$ are moderately anemic and less than $1 \%$ is severely anemic [10]. ALRTI is a leading cause of mortality in children below 5 years of age in developing countries [5]. Hence it is important to control the risk factors to prevent deaths from ALRTI. Thus, the present

Table 5. Clinical Parameters of Anemia in Cases and Controls

\begin{tabular}{llll}
\hline Parameter & Cases & Controls & P value \\
\hline Mean hemoglobin $(\mathrm{g} \%)$ & 9.2 & 11.4 & 0.00 \\
Mean MCV $(\mathrm{fL})$ & 64.49 & 78.36 & 0.00 \\
Mean MCH $(\mathrm{pg})$ & 19.92 & 25.97 & 0.00 \\
Mean MCHC $(\mathrm{g} / \mathrm{dL})$ & 31.13 & 32.52 & 0.00 \\
RDW $(\%$ age $)$ & 17.07 & 13.82 & 0.00 \\
Serum iron $(\mu \mathrm{g} / \mathrm{dL})$ & 36 & 71 & 0.03 \\
Mean serum ferritin $(\mathrm{ng} / \mathrm{mL})$ & 40.21 & 85.15 & 0.00 \\
Mean TIBC $(\mu \mathrm{g} / \mathrm{dL})$ & 396 & 328 & 0.001 \\
\hline
\end{tabular}

study was conducted to prove the fact that anemia may be a risk factor for ALRTI.

Hemoglobin level less than $11 \mathrm{~g} \%$ [8] was considered low in our study subjects. In the present study, anemic group was mainly below 2 years of age with no significant difference between males and females, which is quite comparable with the study conducted by Sheikh et al (2014) [6] and Malla et al (2010) [2]. The common involvement of this age group could be caused by the fact that inadequate and inappropriate supplementary and complementary feeding practices are practiced and advocated widely in this age, due to which hemoglobin could touch the nadir [6].

The patients in the present study had usual clinical presentation of ALRTI, and these findings were consistent with the study conducted by Malla et al (2010) [2]. In our study, 106 of the total number of patients had hemoglobin level below 11 $\mathrm{g} \%$, with $72 \%$ of ALRTI cases and $34 \%$ of non-ALRTI controls. This finding was consistent with the studies conducted by Sheikh et al (2014) [6] and Malla et al (2010) [2]. In comparison to the few other studies done on anemia and ALRTI, Ramakrishnan et al (2006) [11] found that in a study of 200 infants and children between 9 months and 16 years, 74\% of cases and $33 \%$ of controls were anemic (with $80 \%$ and $82 \%$ IDA, respectively). In our study the percentage of anemic children was found to be much higher as compared to the study conducted by Mourad et al (2010) [4], indicating a high prevalence of anemia in Nepal.

Mean serum iron level was $36 \mu \mathrm{g} / \mathrm{dL}$ in the anemic and 71 $\mu \mathrm{g} / \mathrm{dL}$ in the non-anemic ALTRI cases (P value $<0.01$ ), pointing an association of low serum iron in ALTRI, a hypothesis needs consolidation of the previously held research, although the early prospective interventional studies conducted derived the support from the value of iron supplements in reducing rates of respiratory infections in infants. In our study anemic patients had 4.99 OR for developing ALRTI, while it was 3.2, 5.78 and 2.08, as shown in a result that is showing consistent strength of association of anemia and ALTRI.

Few reports are available in literature regarding the role of low hemoglobin level per se, as a risk factor for developing ALRTI. It is feasible to recollect the normal functions of hemoglobin. It facilitates oxygen and carbon dioxide transport. It carries and inactivates nitric oxide and also plays the role of a buffer [12]. Quantitative and/or qualitative reduction in hemoglobin, may adversely affect the normal functions [13]. 
Probably it may be the reason for low hemoglobin level found to be as a serious risk factor for developing ALRTI as found in the present study where anemic children were found to be 4.99 times more susceptible to ALRTI compared to the non-ALRTI control group. Ramakrishnan et al (2006) [11] in their study found that anemic children were 5.75 times more susceptible to ALRTI, which was consistent with our study. Similarly, Savitha et al (2006) [14] did a study on modifiable risk factors for ALTRIs and concluded that anemia was a significant risk factor for ALRTI. As for Broor et al (2001) [15], anemia was not found to be a risk factor for ALRTI in 512 infants and children below 5 years of age.

\section{Limitation of the study}

This study has some limitations, viz. 1) Prevalence of exposure and outcome variables may be different in a community setting as our study was hospital-based. 2) Serum ferritin, a non-specific acute phase reactant can rise in any inflammatory conditions, although both cases and controls were having fever at the time of enrolment. 3) As the sample size was small, a definite conclusion cannot be made on this study alone.

\section{Conclusions}

In the present study, anemia was found to be a risk factor for ALRTI in Nepalese children aged from 6 months to 5 years; hence, early detection and timely correction of anemia may be helpful for prevention of ALRTI in children of this age group.

\section{Acknowledgement}

We thank all the children who had participated in this study. A special thanks to Mrs. Manita Pyakurel Bhatta who had helped with statistical analysis.

\section{References}

1. Kassebaum NJ, Jasrasaria R, Naghavi M, Wulf SK, Johns N, Lozano R, Regan M, et al. A systematic analysis of global anemia burden from 1990 to 2010. Blood. 2014;123(5):615-624.
2. Malla T, Pathak OK, Malla KK. Is low hemoglobin level a risk factor for acute lower respiratory tract infections? J Nepal Pediatric Soci. 2010;30(1):1-7.

3. Lerner NB, Sills R. Iron deficiency anemia. In: Kliegmen RM, Stanton BF, St. Geme JW, Schor NF, Behrman RE, editors. Nelson Textbook of Pediatrics. 19th ed. Philadelphia: Elsevier;2011:1655-1658.

4. Mourad S, Rajab M, Alameddine A, Fares M, Ziade F, Merhi BA. Hemoglobin level as a risk factor for lower respiratory tract infections in Lebanese children. N Am J Med Sci. 2010;2(10):461-466.

5. Kabra SK, Verma IC. Acute lower respiratory tract infection: the forgotten pandemic. Indian $\mathrm{J}$ Pediatr. 1999;66(6):873-875.

6. Sheikh HQ, Ashraf M, Wani JG, Ahmed J. Low hemoglobin level a Risk Factor for acute lower respiratory tract infections (ALRTI) in Children. J Clin Diagn Res. 2014;8(4):1-3.

7. Jitendra P VIJ. IAP Textbook of Paediatrics. 4th ed. Jaypee Brothers Medical Publishers Ltd. 143 pp.

8. Park K. Textbook of Preventive and Social Medicine. 22nd ed. India: Banarasidas Bhanot publishers publication. 2013; Nutrition and Health. 577-578 pp.

9. Lokeshwar MR, Manglani M. Anemia in children. Quarterly Medical Review. 2010;61(2):4-27.

10. Nepal demographic and health survey 2011. Population Division, Ministry of Health and Population Government of Nepal Kathmandu, Nepal. Annual Report 2010/2011:177-178.

11. Ramakrishnan K, Harish PS. Hemoglobin level as a risk factor for lower respiratory tract infections. Indian J Pediatr. 2006;73(10):881-883.

12. Ganong WF. Gas transport between the lungs and the tissues. Review of Medical Physiology: 22nd ed. Phialdelphia: Saunders;2006:507-508.

13. Guyton and Hall. Effect of hemoglobin to 'Buffer' the tissue PO2. Text Book of Medical Physiology. 11th ed. Philadelphia; Saunders, 2006:507-508 pp.

14. Savitha MR, Nandeeshwara SB, Pradeep Kumar MJ, ul-Haque F, Raju CK. Modifiable risk factors for acute lower respiratory tract infections. Indian $\mathrm{J}$ Pediatr. 2007;74(5):477-482.

15. Broor S, Pandey RM, Ghosh M, Maitreyi RS, Lodha R, Singhal T, Kabra SK. Risk factors for severe acute lower respiratory tract infection in under-five children. Indian Pediatr. 2001;38(12):1361-1369. 